\title{
Tailandia: su gente, historia y cultura
}

DOI: $10.32870 /$ mycp.v4i12.122

Roberto Hernández Hernández*

i Quiénes son los tailandeses?, ¿cómo llegaron a ser lo que son?, ¿cómo se perciben a sí mismos?, y ¿cómo los percibimos desde el exterior? La situación actual de este país del sudeste de Asia podrá entenderse mejor con las respuestas que podamos dar a las anteriores interrogantes. Es el propósito de este ensayo.

\section{Los tailandeses}

Los tailandeses actuales son los descendientes de varios grupos étnicos originarios del sur de China y el norte de Vietnam, que a lo largo del tiempo fueron asimilando las influencias culturales de los pueblos vecinos. El idioma thai, por ejemplo, integra estructuras lingüísticas del chino, sánscrito y malayo, así como palabras del mon, khmer, pali y, más recientemente, del inglés. Tanto étnica como lingüísticamente, los thai están emparentados con pueblos de noreste de la India, del oeste y noreste de Vietnam, y del este, sur y centro de la península de Malasia; además de los vínculos que mantienen a través de otras manifestaciones culturales (religión, la literatura y la danza).

$\mathrm{Al}$ igual que otros países del sudeste de Asia, las migraciones que se sucedieron durante varios siglos -a partir del X, en el caso de Tailandia - fueron configurando lo que hoy es este país. Los grupos étnicos actuales de Tailandia son mayoritariamente thai (75 por ciento), seguidos de chinos (14 por ciento).

Las guerras libradas en el pasado por Tailandia contra Myanmar y Camboya movilizaron gran cantidad de refugiados y prisioneros de guerra hacia esta región. Los mon, un pueblo de Myanmar, se establecieron en varias zonas del norte, centro y occidente de Tailandia, aunque ahora se concentran más bien

* Investigador del Departamento de Estudios del Pacífico de la Universidad de Guadalajara.

ORCID http://orcid.org/0000-0002-9145-5865 en un área al oeste de Bangkok. Los khmer, por su parte, se establecieron en el este, a lo largo de la frontera con Camboya. Ambos grupos, de origen lingüístico mon-khmer, de la familia austro-asiática, ahora, en su mayoría, tienen al thai estándar como idioma principal (TNEB 1998).

En términos etnolingüísticos los grupos thai constituyen, por mucho, el grupo predominante del país. Los thai conforman más de la mitad de la población y se ubican en casi todas las áreas del país. Los dialectos thai de las diferentes regiones se diferencian sólo por acentuaciones y algunas palabras. El dialecto más común, conocido como thai estándar (o siamés), es precisamente la lengua nacional que se enseña en todas las escuelas y se utiliza en los medios de comunicación.

Otras dos familias lingüísticas de Tailandia son la malaya, que hablan los habitantes de extremo sur de la península, y la karen, perteneciente a grupos lingüísticos sinotibetanos ubicados en las regiones montañosas del oeste y el norte, los cuales se confunden fácilmente con los thai del norte. Dos pequeñas tribus de montañeses, los lawa (o wa) y semang son de interés especial. Los lawa de habla mon-khmer habitaban las zonas bajas del delta, pero fueron empujados hacia las montañas del noroeste por los thai cuando conquistaron el área (TNEB 1998).

Los chinos constituyen una importante minoría en Tailandia, por su relación con el comercio: operan centros comerciales en Bangkok y otras ciudades, así como pequeñas empresas comercializadoras (intermediarias) y tiendas de barrio.

La prevalencia de varios dialectos del sudeste de Asia se percibe en los comercios, propiedad de sus descendientes. Los de origen hindú, en buena medida, también se dedican al comercio. 
Historia

La historia de Tailandia puede dividirse en dos grandes etapas. La primera corresponde a un desarrollo regional, espontáneo, natural y equilibrado, sobre todo en cuanto a sus relaciones de poder con sus vecinos. Esta etapa, que va del siglo $\mathrm{X}$ al XVIII, no es, en esencia, muy diferente a la de otros países subdesarrollados, que a través de un largo proceso de evolución fueron definiendo su espacio cultural, político y económico frente a los pueblos vecinos por medio de migraciones, comercio, interacción cultural y luchas armadas. Imperios regionales surgían, evolucionaban y declinaban dentro de una dinámica regional propia.

La segunda etapa corresponde a la integración forzosa de Tailandia a la economía y la política mundial, dentro de un esquema de internacionalización en el siglo XIX y de globalización en el XX. En este contexto los tailandeses fueron incorporados por las grandes potencias, en especial Gran Bretaña, a la división internacional del trabajo. Los dirigentes de Tailandia fueron adaptándose, en mayor o menor medida, a los nuevos tiempos, resistiendo las presiones para salvar en algo su país y su nacionalidad. En el marco de la repartición del mundo por las grandes potencias, se dio la apertura económica, así como el ajuste de fronteras con otros pueblos vecinos.

Aunque existen evidencias arqueológicas que indican la presencia casi continua de ocupaciones humanas desde hace 20000 años en lo que hoy se conoce como Tailandia, existen registros de que los pueblos de habla thai se trasladaron hacia el sur y el suroeste desde China y el norte de Vietnam, aproximadamente en el siglo $\mathrm{X}$ de nuestra era.
En los primeros siglos del primer milenio, los pueblos thai se establecieron a lo largo de los valles, de los ríos en tierra firme del norte, sureste, suroeste de Asia y suroeste de China. Conforme los thai se fueron trasladando hacia el sureste de Asia, entraron en contacto con pueblos de habla mon-khmer, donde había grandes extensiones de tierra sin habitar. Los contactos de los thai con la civilización khmer (reino de Angkor) aportaron muchos elementos culturales hindúes en especial los relacionados con las ceremonias reales (particularmente la danza) y la literatura clásica. Muchos de estos elementos pueden encontrarse hasta ahora en las manifestaciones culturales de Tailandia.

Durante el siglo XIII emergieron dos estados thai: el reino Sukhothai, fundado aproximadamente en el año 1220, después de una exitosa revuelta contra el reino Khmer. Durante el reinado de Ramkhamhaeng (12791298) Tailandia se extendió hacia el sur, hasta Nakhon Si Thammarat, al oeste, en lo que hoy es Myanmar, y al noreste, hasta el moderno Laos. No sólo estos territorios fueron conquistados por la fuerza, sino que varios comenzaron a ser vasallos o estados tributarios de los thai basados en lazos de amistad o lealtades personales. El período de Sukhothai se mantuvo desde mediados del siglo XIII hasta elXV.

Pero Sukhothai no fue el único estado thai del sureste de Asia durante este período. A mediados del siglo XIII, en lo que hoy es el norte de Tailandia, un dirigente thai, (Mangrai) conquistó la antigua capital del reino mon de Haripunjaya y estableció la nueva capital de Chiang Mai (fundada en 1296).

En 1350 el estado de Sukhothai fue sucedido por otro reino thai, el de Ayutthaya 
(Audhya). Para principios del siglo XV, éste había absorbido Sukhothai y devastado el declinante estado Khmer (TNEB).

Los birmanos (de Myammar) fueron los rivales más poderosos de los tailandeses durante el reino de Ayutthaya. En 1569 derrotaron al ejército de Ayutthaya, ocuparon su capital y gobernaron durante 15 años (de 1590 a 1605), después de los cuales Ayutthayan recobró su independencia. Sin embargo, el conflicto con Myanmar persistió y a mediados del siglo XVIII, los ejércitos birmanos capturaron de nuevo Ayutthaya. En esta ocasión la ciudad no fue recuperada. Después de un saqueo (1767), el rey y los miembros de la familia real, junto con miles de cautivos, fueron deportados a Myanmar. Todos los registros de Ayutthaya fueron quemados y destruidas sus obras artísticas.

Una nueva era en la historia de Tailandia comenzó con el ascenso de Taksin al poder. Taksin fue un comandante de gran capacidad y carisma que exitosamente empujó hacia atrás a los birmanos y restableció el poder político de los thai, con capital en Thon Buri. Asimismo, restableció las relaciones comerciales que Siam (como se conocía a Tailandia en ese tiempo) había tenido con China y estimuló a los comerciantes y artesanos chinos a aprovechar las ventajas y oportunidades que ofrecía la nueva capital al otro lado del río Chao Phraya, más segura y con mejor acceso que la anterior. Taksin no sólo recuperó los territorios que habían formado parte del imperio Ayutthayan, sino que extendió el control sobre nuevas áreas: anexó parte de lo que hoy es el noreste de Camboya y avanzó sobre el río Mekong hasta lo que hoy es Vientiane y Laos. En el Sur controló la parte norte de la península de Malasia. A los pocos años de estar en el poder, Taksin mostró signos de seria inestabilidad mental, y en 1782 fue destronado y sucedido por quien fuera su comandante militar, Chao Phraya (Gran Señor) Chakri. Como Rama I, Chakri inició la dinastía que hasta la actualidad permanece en el trono (TNEB 1998).

Los reyes Chakri en una primera etapa restauraron la herencia cultural de Ayutthaya: los nuevos templos y palacios fueron construidos siguiendo el mismo estilo, utilizando los ladrillos que habían embellecido Auyutthaya. Rama I restableció los rituales de la corte, emitió leyes y códigos y reeditó los textos budistas; apoyó la recuperación de la Sangha (sistema monástico budista) e incorporó a eruditos y monjes budistas en posiciones directivas de su gobierno. El período temprano de Bangkok fue también de gran florecimiento literario.

Durante el siglo XIX las presiones de las potencias europeas sobre Tailandia para obtener ventajas y concesiones políticas, económicas, comerciales y territoriales se incrementaron sustancialmente, tal como sucedía en el resto del mundo. Cuando Gran Bretaña declaró la guerra a Myanmar en 1824, Rama III temió que hiciera lo mismo sobre Siam. En este ambiente se vio obligado a firmar el tratado Burney (1826), que establecía las condiciones para conducir las relaciones comerciales entre los dos países.

Las demandas de libre comercio y apertura de representaciones diplomáticas en Siam se vieron aceleradas con la penetración de Gran Bretaña sobre Myanmar y Malasia, así como con la apertura de varios puertos chinos, producto de la Primera Guerra del Opio (1839-1842).

En 1855 la reina Victoria envió a Sir John Bowrin como su emisario personal para presionar a Tailandia y poner fin a toda restricción comercial, así como para asegurar los derechos de establecer un consulado británico en Bangkok y permitir la vigencia de leyes 
británicas para tratar los casos de los súbditos ingleses (extraterritorialidad).

El tratado fue sólo una parte de la estrategia global del capitalismo británico en la lucha por la hegemonía del este y el sudeste de Asia, librada contra las potencias de la época. Estos movimientos habían comenzado con la ocupación de Singapur en 1829, seguida de la ocupación militar de Malaca (1824), de la Alta Birmania (1824-1826), los asentamientos de los estrechos (1826), Hong Kong (1842) y la Baja Birmania (1852), para culminar con el control directo y total de la India (1858). Además de estos controles políticos y militares, Gran Bretaña obligó la firma de tratados comerciales con China (Nanking en 1842 y Tiensin en 1858), lo mismo que con Japón en 1858 (Suehiro 1989: 17).

En este contexto y como producto del tratado Bowring (1855), Tailandia se vio forzada a firmar tratados similares con otras potencias europeas y con Estados Unidos, las cuales inmediatamente demandaron concesiones similares, como se acostumbraba en esa época. Aunque estos tratados no convertían formalmente a Tailandia en una colonia, ello implicaba una seria disminución en su soberanía y su independencia. Entre finales del siglo XIX y principios del XX, Tailandia se vio obligada a ceder a Francia los estados vasallos que mantenía en lo que hoy es Laos y Camboya.

Para finales del siglo XIX la economía de Tailandia había sido forzada a especializarse en tres productos de exportación: arroz, madera de teca y estaño. Las industrias manufactureras estuvieron esencialmente restringidas al procesamiento de estos productos de exportación. Las pocas industrias locales existentes fueron, en su mayoría, eliminadas por la competencia de bienes manufacturados de Europa y de otros países de Asia. Junto con esto, por medio de los tratados desiguales firmados con las potencias, Tailandia fue forzada a establecer el impuesto a las importaciones más bajas de Asia (3 por ciento). Este país habría de recuperar su autonomía fiscal hasta 1929 (Suehiro 1989: 274). La pérdida de importantes recursos financieros que el gobierno de Tailandia obtenía por concepto de ingresos aduanales —su principal fuente de recursos-, la forzó a buscar en la población local nuevas fuentes de financiamiento.

En esta etapa Tailandia experimentó una transición en su patrón de comercio, de regional a mundial, dentro de un esquema colonial que tenía como centro a Gran Bretaña. En otras palabras, la economía de Tailandia se integró a una división internacional del trabajo asiática, en la cual la región cumplía el papel de abastecedora de materias primas a cambio de proveer su mercado interno con bienes manufacturados procedentes de Europa.

La integración de Tailandia a la política mundial se manifestó con su participación en las dos guerras mundiales: en la primera se involucró a favor de los aliados y en la segunda - a regañadientes - se convirtió en aliado de Japón.

En los últimos 70 años, los militares han tenido un papel muy activo en la política del país. En 1932 se dio un golpe de Estado que puso fin al absolutismo de la monarquía; el rey Prajadhipik, que siguió gobernando hasta 1935, estableció un régimen constitucional. Desde 1932 se han sucedido una serie de gobiernos militares o fuertemente influenciados por la clase castrense. El poder de la monarquía ha sido, desde entonces, muy limitado.

Las guerras de Indochina y Vietnam, así como las excursiones de este último país sobre Camboya, han afectado la estabilidad de Tailandia, que si bien ha mantenido una política de neutralidad frente a los conflictos regionales, no ha logrado impedir que su territorio se convierta en santuario de grupos armados inconformes contra los gobiernos de sus vecinos.

Después de la Segunda Guerra Mundial, los gobiernos se involucraron en una política de promoción industrial y de exportaciones de manufacturas. Para ello se dio una intensa introducción de capitales externos y tecnología, sobre todo de las empresas transnacionales 
apoyadas con estímulos gubernamentales. Un desarrollo típicamente capitalista se ha dado a partir de los años sesenta, respaldado por tres tipos de agrupaciones: 1) las empresas gubernamentales, incluyendo las fábricas de armamentos, 2) las empresas transnacionales y 3) el grupo de empresarios tailandeses, en su mayoría de origen chino (Suehiro 1989: 275). Con estos elementos, Tailandia se ha incorporado a la nueva división internacional del trabajo, que le da sentido y racionalidad a los flujos de capital y tecnología para aprovechar los recursos disponibles del país, incluyendo la mano de obra barata. En este contexto de integración económica y política, la influencia externa se ha presentado en todos los órdenes de la vida de los tailandeses.

Arte

El arte de Tailandia tiene una gran influencia religiosa, en especial del budismo; en este aspecto, sobresale la escultura. La pintura, muy probablemente sigue los modelos de India y de Sri Lanka, y se manifiesta también a través de temas religiosos. La pintura realizada por monjes anónimos, o dedicada por el pueblo, se manifiesta comúnmente en los muros de los templos. La música comparte grandes afinidades con la de Laos y Camboya; existen tres orquestas típicas: pi phat, que se utiliza en las ceremonias de la corte y el teatro; kruang sai ques, que se ejecuta en los pueblos y los teatros, y mahori, que acompaña a los vocalistas (TNEB).

\section{Danza, drama y teatro}

La danza, el drama y el teatro en Tailandia han evolucionado desde sus orígenes folclóricos y religiosos hasta sus más refinadas, sofisticadas y ritualistas presentaciones, como las que se realizan en la corte. Estas representaciones artísticas han sido parte vital de la cultura tailandesa. Sus originales funciones ceremoniales se relacionan principalmente con la agricultura (plantación y cosecha del arroz), así como con las plegarias para la lluvia, y se mantienen aún activas tanto en las zonas rurales como en las urbanas.

En la ceremonia anual de plantación del arroz, el rey de Tailandia, hasta la actualidad, cumple con el importante papel de padre plantador de arroz, quien distribuye los mejores granos para su pueblo y representa la ceremonia de siembra. El rey también preside la ceremonia de petición de buen clima, por medio de los bueyes sagrados de los brahmanes. En todas estas ceremonias reales y folclóricas, las danzas (algunas dramatizadas) son ejecutadas para satisfacer a los dioses patronales y a los espíritus de los fenómenos naturales y la agricultura. Por cierto, en dichas ceremonias intervienen el budismo, el brahmanismo, y el hinduismo, junto con las creencias animistas, la superstición y la magia de las primitivas manifestaciones culturales folclóricas.

Es importante hacer notar que la monarquía Thai ha jugado un papel importante en términos políticos, sociales, económicos y culturales, en el desarrollo y la representación misma de las manifestación artísticas, desde los primeros tiempos históricos hasta nuestros días. Aunque el golpe de Estado de 1932 removió a la monarquía tailandesa de su papel directo en la política, las ceremonias relacionadas con

la monarquía y las manifestaciones religiosas con las masas populares fueron revividas en los años cincuenta por los propios militares.

En el pasado, una vez que las artes y las danzas folclóricas regionales fueron adoptadas por la corte, comenzaron a ser prerrogativa de la realeza y tabú para el público en general. La Lakhon Phuying Khong Luang (la danza dramática femenina de la corte real) fue posesión exclusiva del rey y guardada celosamente por la institución real. El mantenimiento de este tabú originó varios incidentes políticos, sobre 
todo durante el reinado de Rama I. Fue hasta el reino del Mongkut (Rama IV) en el período de Bangkok, durante el siglo XIX, que este tabú fue eliminado y a los grupos privados de teatro y danza se les permitió entrenar a sus propias artistas de danza-drama en el estilo de la corte real (Mattani 1993: xiii, xiv y 1-13)

\section{Religión}

Los tailandeses, en su gran mayoría, profesan el budismo. De acuerdo con datos de 1991, los budistas representan 95 por ciento; los musulmanes 3.8 por ciento, los cristianos, 0.5 por ciento; los hinduistas 0.1 por ciento, y el restante 0.6 por ciento correspondía a otras creencias (CIA 1997).

El budismo apareció en Tailandia desde el siglo III a. C., cuando el emperador Asoka (267-227) de la India despachó misioneros al sudeste de Asia a propagar la fe que recientemente había establecido en su reino. En Nakhon Pathom todavía se conservan enormes monumentos budistas de la época.

La mayoría de los budistas tailandeses son de la escuela Theravãda. Además de los thai, los khmer, los mon y algunos miembros de otras minorías - como los chinos-pertenecen a esta corriente religiosa. Algunos thai profesan el budismo Mahayana u otras religiones, como el hinduismo, el cristianismo, el taoísmo, el animismo o el islamismo.

El budismo es la religión oficial de Tailandia. El rey, de acuerdo con la constitución y la tradición, es budista. (El budismo está representado en la bandera nacional por dos líneas blancas.) Actualmente, el gobierno tiene un sistema parlamentario, con el rey como jefe de Estado, a quien ya no se le considera como un dios. No obstante lo anterior, la ley en Tailandia no es budista, sino en gran medida secular y no existen restricciones de proselitismo para las otras religiones, ni presión alguna hacia el pueblo para que practique alguna en especial (Maidment 1998: 123). En términos populares, al rey se le considera defensor de las religiones que profesan las diversas comunidades, situación que refuerza la libertad y la tolerancia hacia toda práctica religiosa.

El budismo se asocia también con el respeto y la veneración hacia la monarquía, la cual históricamente ha apoyado a su estructura jerárquica (Sangha). Esto es correspondido por los monjes con la legitimación de la realeza.

La religión continúa siendo muy importante en el estilo de vida de la población. Los monasterios ofrecen refugio para los hombres que desean retirarse por un tiempo determinado. Es frecuente que el padre de familia se retire a un monasterio después de la muerte de su esposa. Prácticamente cada hombre tailandés se convierte en monje, por lo menos tres meses de su vida, durante su juventud. Para recolectar el apoyo de la comunidad, que cotidianamente les dan ofrendas, los monjes caminan alrededor del monasterio. Los templos budistas son también el refugio para perros y gatos extraviados que acuden a éstos sabiendo que serán alimentados por los monjes (RI).

Los musulmanes constituyen una significativa minoría y viven principalmente en el sur. La mayor parte de la pequeña comunidad de cristianos vive en la región central, lo mismo que los hindúes, alrededor de Bangkok. Aunque algunas de la tribus de la montañas se han convertido al budismo o al cristianismo, la mayoría de su miembros continúan siendo animistas (TNEB 1998).

Un aspecto muy particular de la vida religiosa de los tailandeses es la considerable influencia de los brahmanes hindúes, aún cuando ellos suman sólo unos pocos miles de familias. La mayoría de las ceremonias reales y oficiales son casi en su totalidad dirigidas o representadas por los brahmanes, cuyos ritos son matizados, en forma armoniosa con los de los budistas. Los brahmanes son reconocidos por sus experiencia astrológica, asumen responsabilidades para la preparación del calendario nacional y ofician ceremonias estatales, como la de arar, que se realiza anualmente, y se cree trae una buena cosecha 
de arroz. No existen importantes movimientos religiosos nuevos en Tailandia, pero los monjes budistas han comenzado a involucrarse en asuntos ambientales y sociales (TNEB 1998).

\section{Lenguaje}

El tailandés (o siamés) corresponde al lenguaje estándar, perteneciente a la familia thai del sudeste de Asia. Está basado principalmente en el dialecto de Bangkok y su periferia. Las palabras thai son en su mayoría monosilábicas. El lenguaje utiliza tonos para diferenciar palabras que de otra forma serían fonéticamente iguales. La lengua thai incorpora con libertad palabras de otros idiomas. Quizá las más antiguas sean chinas, aunque recientemente todavía se siguen incorporando toponimios chinos. Cientos de palabras elegantes y literarias son tomadas del pali y del sánscrito, y otras nuevas son acuñadas con raíces del sánscrito. También existen topónimos del khmer (el lenguaje oficial de Camboya), del portugués del siglo XIV y del austropolinesio. En los últimos tiempos también se ha incrementado la incorporación de palabras del inglés; idioma utilizado en Tailandia, en especial en las zonas urbanas. Esta lengua es una asignatura obligatoria en la educación media (TNEB 1998).

\section{Conclusiones}

Por cultura tailandesa se entiende un conjunto de valores, conductas y modo de ser, enraizados en la historia del pueblo thai. Prácticamente todos los grupos étnicos de Tailandia, tengan o no sus orígenes en los pueblos que migraron del norte, han sido asimilados a la corriente principal conocida como thai.

Desde principios del segundo milenio de nuestra era, los tailandeses fueron delimitando su espacio político y económico, frente a otros pueblos de la región, algunos de éstos emparentados étnica y lingüísticamente con los thai.

La incorporación forzosa de Tailandia a la economía y la política mundiales, la han mantenido en una situación de dependencia frente a los países hegemónicos. Este país constituye un caso típico de un imperio regional, convertido en un enclave colonial, aunque nunca formalmente haya sido una colonia. Como país subdesarrollado busca la forma de avanzar hacia mejores estadios económicos y sociales, en contextos muy difíciles y restrictivos, determinados por la nueva división internacional del trabajo configurada después de la Segunda Guerra Mundial.

En Tailandia conviven, asimismo, las particularidades culturales definidas en los últimos mil años, con la globalidad impuesta por el mundo moderno; circunstancia de la cual se enorgullecen los tailandeses que muestran una tendencia hacia el sincretismo a través de la negociación y aceptación de las diferencias. La asimilación de las diversas corrientes culturales, como el lenguaje y la religión al ser nacional de Tailandia, no implican un abandono de los valores ya interiorizados. La «occidentalización» no significa el olvido de sus tradiciones: junto al uso de algunas prendas de vestir extranjeras y la proliferación de automóviles, cinemas y supermercados, persisten el respeto hacia la vida monástica y la monarquía, la continuación de las tradiciones y las festividades, incluyendo la danza y el teatro.

Cabe señalar, por último, que la inserción de Tailandia a la economía y las política mundial no ha sido ajena a la realidad de México. Desde hace varios siglos ambos países forman parte de un sistema global que interactúa e influye simultáneamente sobre ellos.

\section{Fuentes}

CIA. 1997 CIA World Factbook Report on Thailand; Mattani, Mojdara Rutnin (1993) Dance, drama, and theatre in Thailand: the process of development and modernization, Silkworms Books, Chiang Mai, Thailand; Maidment, Richard y Mackerras, Colin (eds.) (1998) Culture and society in the Asia-Pacific. Routledge, Londres y Nueva York; RI. Religion in Thailand (http://www.sec.nl/persons/stals/ nns97/); Suehiro, Akira (1989) Capital Accumulation in Thailand, 1855-1985. Silkworm Books, Bangkok, Thailand. TNEB. The New Encyclopaedia Britanica: 1998, Micropedia y Macropedia, 15 edición. I!: 